\title{
Atmospheric Pressure Photoionization Mass Spectrometry of Polyisobutylene Derivatives
}

\author{
Sándor Kéki, János Török, Lajos Nagy, and Miklós Zsuga \\ Department of Applied Chemistry, University of Debrecen, Debrecen, Hungary
}

\begin{abstract}
Atmospheric pressure photoionization mass spectrometric (APPI-MS) study on three types of polyisobutylene derivatives is reported. Two of the polyisobutylenes investigated were polyisobutylene with dihydroxy and diolefinic end-groups derived from aromatic moieties [dicumyl chloride, 1,4-bis(2-chloro-2-propyl)benzene], and the third contained no aromatic moieties with a monohydroxy end-group. All three polyisobutylene derivatives (PIBs) had an average molecular weight $\left(M_{\mathrm{n}}\right)$ of $\sim 2000 \mathrm{~g} / \mathrm{mol}$, with a polydispersity lower than 1.2. In the positive ion APPI mode, protonated PIB molecules were formed, but the molecular weights obtained were considerably lower than those expected, indicating fragmentation of the PIB chains. In the negative APPI mode, using solvents such as tetrahydrofuran and toluene as dopants, no signal was obtained. However, in chlorinated solvents, such as $\mathrm{CCl}_{4}, \mathrm{CHCl}_{3}$, and $\mathrm{CH}_{2} \mathrm{Cl}_{2}$, in the presence of toluene dopant, PIB adducts with chloride ions were formed with relatively high signal intensity. In the case of $\mathrm{CH}_{2} \mathrm{Cl}_{2}$, no dopant (toluene) was necessary to generate chlorinated adduct ions, albeit increasing the toluene concentration in the flow increased the PIB signal intensity. The effect of the toluene concentration on PIB signal intensity was studied and models that include (1) photoionization of toluene, (2) formation of chloride ions from the chlorinated solvents by dissociative electron capture, (3) formation of chlorinated adduct ions and charge recombination reactions between the toluene radical cation, (4) chloride ions, and (5) chlorinated adduct ions are proposed based on the experimental results. (J Am Soc Mass Spectrom 2008, 19, 656-665) (c 2008 American Society for Mass Spectrometry
\end{abstract}

$\mathrm{P}$ olymer characterization, including the determination of molar mass, molar mass distribution, the mass of the repeat unit and end-groups, and functionality, is an important process that can be accomplished using several methods. Mass spectrometric methods, particularly those that utilize soft-ionization techniques, e.g., matrix-assisted laser desorption/ionization (MALDI) [1,2] or electrospray ionization (ESI) [3], are superior to other methods because they offer a unique capability to determine all of these parameters. Contrary to other spectroscopic methods, such as nuclear magnetic resonance (NMR), which can only determine an average value of some of the above parameters [e.g., the number-average molecular weight $\left(M_{n}\right)$ and number average-functionality $\left.\left(F_{\mathrm{n}}\right)\right]$, mass spectrometric methods provide not only these average values, but the individual intact polymer molecules can also be detected. However, because soft-ionization is based on forming adduct ions with metal ions, e.g., alkali or silver ions or through protonation and/or deprotonation, mass spectrometric analysis of polymers having moieties that are unable to form ions presents difficulties. This is more pronounced as the polarity of the polymers decreases. For example, mass spectrometric

Address reprint requests to Dr. Miklós Zsuga, Department of Applied Chemistry, University of Debrecen, H4010 Debrecen, Hungary. E-mail: zsugam@tigris.klte.hu analysis of polar polymers such as polyethylene glycol (PEG) and polypropylene glycol (PPG) can easily be achieved using MALDI and/or ESI [3-10]. Nonpolar polymers such as polystyrenes are also amenable to MALDI and ESI through the formation of silver- or copper-cationized adduct ions [11-14]. In this case, however, relatively high ionization efficiency can be expected because each monomer unit in the polystyrene backbone carries unsaturated moieties to which silver or copper ions can effectively attach. Mass spectrometric analysis of other industrially important nonpolar polymers, especially those composed of saturated, nonpolar moieties, e.g., polyisobutylenes, usually fails due to the lack of effective sites for ionization. Recently, we have shown that MALDI-spectra of good quality can be obtained by introducing aromatic moieties (e.g., using aromatic initiators for initiation of the isobutylene polymerization) and/or polar groups into the polyisobutylene chain [15-18]. Good spectral quality in the negative ion mode under MALDI conditions can also be attained by modifying the olefin end-groups of polyisobutylene to $-\mathrm{SO}_{3} \mathrm{H}$ [19]. Low molecular weight polyisobutylenes with succinic anhydride end-groups were analyzed by ESI in the negative ion mode [20]. In this case, the anhydride was hydrolyzed to a carboxylic acid end-group that is capable of forming a negative charge under ESI. However, this method requires both the presence of a highly polar group in the PIB (that can 


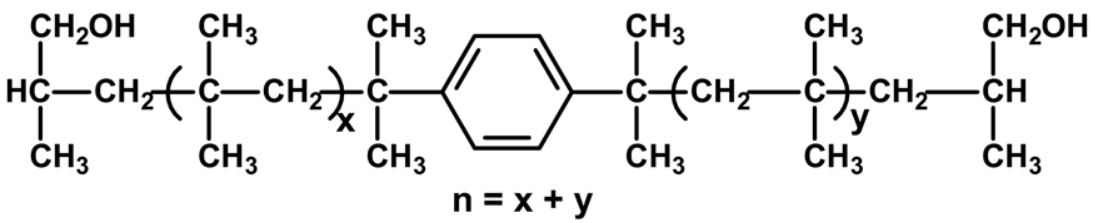

(a)

(HO-PIB-OH)
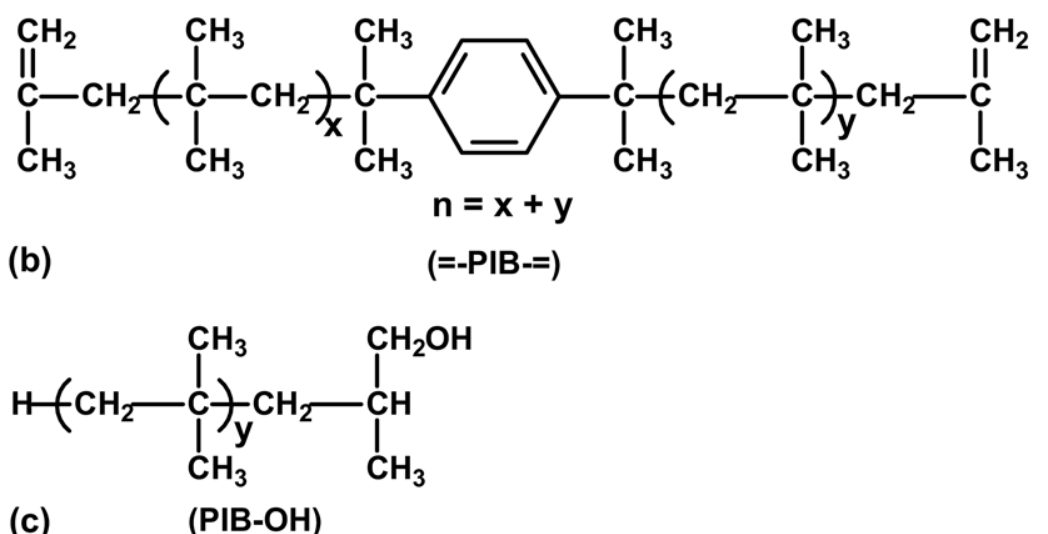

(c)

(PIB-OH)

Scheme 1. Structures of polyisobutylene with dihydroxy (a), diolefin (b), and monohydroxy termini (c).

easily be ionized) and an ESI-compatible solvent or solvent mixture. Unfortunately, these solvents are incompatible with polyisobutylenes, especially above a molecular weight of $1000 \mathrm{~g} / \mathrm{mol}$ (due to the very poor solubility of PIBs in these solvents). Very recently, a new ionization method called atmospheric pressure photoionization (APPI) has been developed to broaden the range of analytes that are useful for MS analysis, especially for compounds of low polarity $[21,22]$. This method has been used to successfully analyze several classes of nonpolar compounds, including polyaromatic hydrocarbons [23-25], lipids [26-28], and steroids [29-31]. This technique is based on the direct or indirect photoionization of the analyte by vacuum UV (VUV) photons generally emitted from a $\mathrm{Kr}$ discharge lamp. Photoionization is very often performed in the presence of a dopant, e.g., toluene or acetone, to increase ionization efficiency (dopant-assisted APPI).

In this article, we report a detailed APPI-MS study on polyisobutylenes that are only slightly ionizable under MALDI or ESI conditions or not at all. We show that singly charged PIB adducts with chloride ions can be generated in the negative ion mode of APPI-MS using chlorinated solvents $\left(\mathrm{CCl}_{4}, \mathrm{CHCl}_{3}\right.$, and $\left.\mathrm{CH}_{2} \mathrm{Cl}_{2}\right)$ in the presence of a toluene dopant, allowing the MS analysis of polymers of such a low polarity.

\section{Experimental}

\section{Chemicals}

The PIB derivatives that were investigated are summarized in Scheme 1.
HO-PIB-OH and = -PIB- = were prepared by living cationic polymerization according to the method described in Ref 15 . PIB-OH was synthesized similarly to those described in Ref 15, but 2-chloro-2,4,4-trimethylpentane (TMPCl) was used as the initiator instead of dicumyl chloride (1,4-bis(2-chloro-2-propyl)benzene), and $\mathrm{TiCl}_{4}$ was used as a co-initiator for isobutylene polymerization. All other reagents were received from Sigma-Aldrich (Seelze, Germany). Each solvent was of HPLC grade. The polymers were characterized by ${ }^{1} \mathrm{H}-$ NMR, ${ }^{13} \mathrm{C}-\mathrm{NMR}$, and size-exclusion chromatography (SEC).

\section{Instrumentation}

APPI quadrupole time-of-flight mass spectrometric (APPI-Qq-TOF MS) measurements were performed in the positive and negative ion modes with a MicroTOF-Q type Qq-TOF MS instrument (Bruker Daltonik $\mathrm{GmbH}$, Bremen, Germany) equipped with an APPI source (PhotoMate Kr discharge lamp, VUV photons of 10.0 and $10.6 \mathrm{eV}$ in intensity ratio of 4:1, respectively) from Syagen Ltd. (Syagen Technology, Inc., Tustin, CA). PIBs were dissolved at a concentration of $0.5 \mathrm{mM}$ in mixtures of toluene (dopant) and Solvent $\mathrm{S}$, where

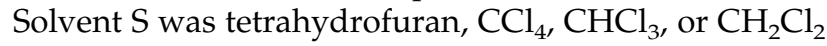
in a volume ratio (vol/vol) of $0,0.1,0.2,0.4,0.6$, and 0.8 (toluene/S). The PIB solutions were introduced directly into the APPI source with a syringe pump (Cole-Parmer Ins. Co., Vernon Hills, IL) at a flow rate of $25 \mu \mathrm{L} / \mathrm{min}$ together with a carrier flow of solvent $\mathrm{S}$ at a flow rate of $200 \mu \mathrm{L} / \mathrm{min}$ by means of a T-piece. The APPI source heater was kept at $400{ }^{\circ} \mathrm{C}$. The total volumetric gas flow 
$\left(\mathrm{N}_{2}\right)$ was estimated to be about $50 \mathrm{~cm}^{3} / \mathrm{s}(3 \mathrm{~L} / \mathrm{min}, 2$ bar). End-plate offset and capillary voltage were set to $-500 \mathrm{~V}$ and $4000 \mathrm{~V}$, respectively.

The precursor ions for the MS/MS experiments were selected with an isolation width of $\pm 1-2 \mathrm{Th}$, and collision energy 5-40 eV (in the Lab frame) was used.

All the spectra were recorded by a digitizer at a sampling rate of $2 \mathrm{GHz}$. The spectra were calibrated externally with the APCI/APPI calibrant mixture from Agilent Technologies, Inc., Santa Clara, CA, in the $\mathrm{m} / \mathrm{z}$ range $600-1600$. The accuracy of the $\mathrm{m} / \mathrm{z}$ determination was within $\pm 0.01 \mathrm{Th}$. The recorded mass spectra were evaluated using the DataAnalysis 3.1 software from Bruker.

\section{Results and Discussion}

\section{APPI-MS in the Positive Ion Mode (APPI(+)-MS)}

The positive APPI-MS spectra of HO-PIB-OH, = -PIB$=$ and PIB-OH (see Scheme 1), which were obtained in tetrahydrofuran, hexane, and chlorinated solvents such as $\mathrm{CCl}_{4}, \mathrm{CHCl}_{3}$, and $\mathrm{CH}_{2} \mathrm{Cl}_{2}$, revealed that protonated molecules of these polymers $\left([\mathrm{M}+\mathrm{H}]^{+}\right)$formed. The formations of $[\mathrm{M}+\mathrm{H}]^{+}$ions were supported by accurate mass measurements. For example, the measured/ calculated monoisotopic $\mathrm{m} / \mathrm{z}$ values for the [= -PIB- = $+\mathrm{H}]^{+}$ions with $n=21,22$, and 23 were found to be $1448.5649 / 1448.5566,1504.6281 / 1504.6192$, and 1560.6898/ 1560.6818 , respectively.

However, the most probable peak appeared at $\mathrm{m} / \mathrm{z}$ values $(\sim m / z$ 1500-1600) that were considerably lower than expected on the basis of their $M_{\mathrm{n}}$ values $(\sim \mathrm{m} / \mathrm{z}$ 2000) and relative narrow polydispersity (a representative APPI(+)-MS spectrum is shown in the Supplementary Material, which can be found in the electronic version of this article). In addition, the obtained APPI(+)-MS intensity distribution of PIBs is skewed to the lower $\mathrm{m} / \mathrm{z}$ range. These observations may indicate the presence of protonated PIB chain fragments. Although APPI(+)-MS may not be favorable for analyzing intact PIB chains, it can be very useful when performing MS/MS experiments. Indeed, by selecting some peaks for MS/MS experiments, protonated PIB molecules can easily be fragmented at moderate collision energies to generate product ions, each differing by $56 \mathrm{Da}$, i.e., mass of an isobutylene repeat unit, as a result of successive chain-breaking events that are probably initiated by the positive charge (a representative APPI $(+)$ MS/MS spectrum is presented in the Supplementary Material). It was not necessary to use toluene as a dopant to perceive APPI(+)-MS spectra in either solvent. However, application of a dopant slightly increased signal intensity. For example, using toluene as the solvent for HO-PIB-OH in the sample flow (sample flow rate with toluene: $25 \mu \mathrm{L} / \mathrm{min}$, carrier flow rate with THF: $200 \mu \mathrm{L} / \mathrm{min}$ ) increased the signal intensity only by ca. $20 \%$ compared with the case in which no

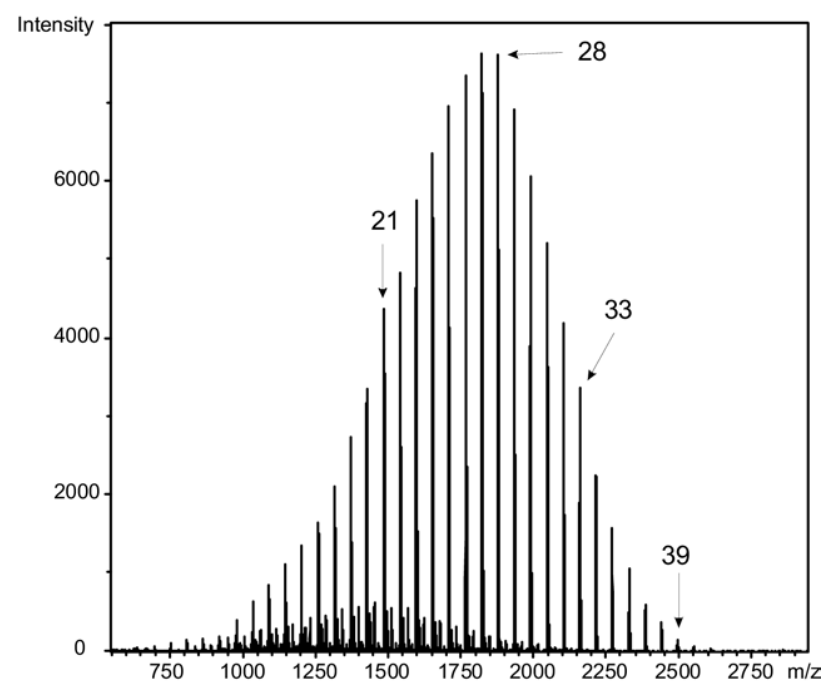

Figure 1. Negative ion atmospheric pressure photoionization mass spectrum of diolefin telechelic polyisobutylene ( = -PIB- $=$ ) in $\mathrm{CCl}_{4}$ at a toluene concentration of $0.067 \mathrm{vol} / \mathrm{vol}$. The toluene concentration represents the volume fraction of toluene with respect to the total (sample and carrier) feed. The = -PIB- = concentration in the sample feed was $0.5 \mathrm{mM}$. The numbers at the top of some peaks represent the numbers of the repeat units, as shown in Scheme 1a. (Total flow rate: $225 \mu \mathrm{L} / \mathrm{min}$ ).

dopant was used (sample flow rate with THF of 25 $\mu \mathrm{L} / \mathrm{min}$, carrier flow rate with THF of $200 \mu \mathrm{L} / \mathrm{min}$ ).

\section{APPI-MS in the Negative Ion Mode (APPI(-)-MS)}

In the negative ion mode of APPI-MS, no signals were obtained for any of the three PIB derivatives using sample and carrier flow with THF or hexane in the absence or presence of a dopant (toluene). However, considerable signal intensities were recorded for each PIB derivative when chlorinated solvents were used. As a representative example, the APPI(-)-MS spectrum of $=-\mathrm{PIB}-=$ using $\mathrm{CCl}_{4}$ carrier flow and toluene dopant is presented in Figure 1.

Figure 1 shows the distributions of PIB oligomers from $\mathrm{m} / \mathrm{z} 700$ to $\mathrm{m} / \mathrm{z} 2600$, i.e., corresponding to the number of isobutylene repeat units from $n=7$ to $n=$ 41. The distribution is narrow, indicating the living nature of the polymerization process [15]. However, it is also evident based on the APPI(-)-MS spectrum that the negatively charged ions are due to the adducts of $=$ -PIB- $=$ with the chloride ion, i.e., $[\mathrm{M}+\mathrm{Cl}]^{-}$. Our results indicate that each PIB derivative forms adduct ions $[\mathrm{M}+\mathrm{Cl}]^{-}$in the presence of chlorinated solvents in the gas-phase under APPI conditions. This was unambiguously supported by comparing the experimental and theoretical isotopic distributions calculated using the elemental compositions for some oligomers, as well as by accurate mass measurement. For example, the calculated monoisotopic value of $\mathrm{m} / \mathrm{z}$ for the chlorinated adduct of $=$-PIB- $=$ with $n=28$ (elemental 


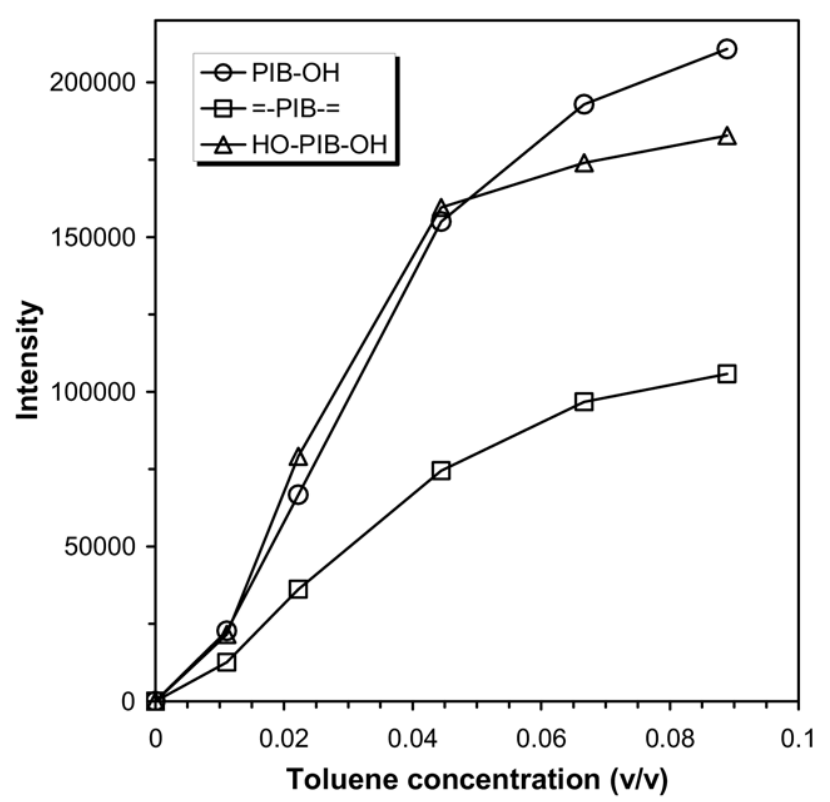

Figure 2. Signal intensity variation recorded in $\mathrm{CCl}_{4}$ for the polyisobutylene derivatives as a function of toluene concentration. The toluene concentrations represent the volume fractions of toluene with respect to the total (sample and carrier) feed. The concentration of the PIB derivatives in the sample feed was 0.5 $\mathrm{mM}$. (Total flow rate: $225 \mu \mathrm{L} / \mathrm{min}$ ).

composition: $\mathrm{C}_{132} \mathrm{H}_{254} \mathrm{Cl}$ ) was 1874.9570 , while the measured value was 1874.9611 .

The chloride ion probably interacts with the $\mathrm{H}$ atoms of the methyl groups of the isobutylene units as well as with those of the end-groups. Each $\mathrm{H}$ atom of the methyl groups of polyisobutylene has a partial positive charge. However, chloride ions are most likely to attach to the $\mathrm{H}$ atoms of the hydroxyl and vinyl end-groups because the positive charge on these $\mathrm{H}$ atoms is higher than on those of the monomer. Therefore, the chloride ion is able to attach to these $\mathrm{H}$ atoms by secondary chemical forces, which was further supported by MS/MS experiments. The MS/MS experiments performed on some precursor ions showed that an increase of the collision energy resulted in no detectable formation of any product ion and led to the complete loss of the precursor ion signal. This may indicate that the adducts dissociated into neutral polymer and chloride ions. (Unfortunately, the $\mathrm{m} / \mathrm{z}$ value of $\mathrm{Cl}^{-}$is lower than the lowest $m / z$ reachable with our Qq-TOF instrument). The dependences of the APPI(-)-MS signal intensity upon the toluene concentration and the solvent were studied for each PIB derivative. The variations of the $\mathrm{APPI}(-)-\mathrm{MS}$ signal intensities against the toluene concentration for the HO-PIB-OH, = -PIB- =, and PIB-OH in $\mathrm{CCl}_{4}$ are shown in Figure 2. The corresponding signal intensity plotted on the $y$-scale is the sum of all of those oligomer peaks that appeared in the APPI(-)-MS spectra.

Figure 2 shows that no detectable signal was obtained in either case in the absence of dopant. However, the APPI(-)-MS signal intensity increases rapidly with the toluene concentration at relatively low concentra- tions, and this signal enhancement tends to decrease at higher concentrations. It is also interesting to note that, although HO-PIB-OH and = -PIB- = differ only in their end-groups, $\mathrm{HO}-\mathrm{PIB}-\mathrm{OH}$ produces a stronger $\mathrm{APPI}(-)-\mathrm{MS}$ signal with increasing toluene concentration than = -PIB- = (both contain an aromatic moiety in the middle of the backbone and consist of approximately the same number of repeat units). This is also true for the other two chlorinated solvents, $\mathrm{CHCl}_{3}$ and $\mathrm{CH}_{2} \mathrm{Cl}_{2}$. It should be noted that only a very weak, nonevaluable APPI(-)-MS signal for = -PIB- = could be obtained in $\mathrm{CHCl}_{3}$. Figure 2 indicates that the variations of the APPI(-)-MS signal intensity against the toluene concentration for PIB-OH and HO-PIB-OH (both consist of approximately the same number of repeat units, but $\mathrm{PIB}-\mathrm{OH}$ does not contain aromatic moiety) are very similar. This is also true for when $\mathrm{CH}_{2} \mathrm{Cl}_{2}$ was used, albeit significant fragmentation by loss of a water molecule was observed (this will be discussed later).

However, the APPI(-)-MS signal intensity increases more rapidly with the toluene concentration for $\mathrm{HO}$ $\mathrm{PIB}-\mathrm{OH}$ than for $\mathrm{PIB}-\mathrm{OH}$ when using $\mathrm{CHCl}_{3}$. It is evident from the above results that the solvent also affects the resulting APPI(-)-MS signal intensities. To demonstrate the solvent effect on the APPI(-)-MS intensities, the dependence of the APPI(-)-MS signal intensity versus toluene concentration is plotted for the PIB-OH using various chlorinated solvents (Figure 3).

As evident in Figure 3, the highest APPI(-)-MS intensity with increasing toluene concentration can be obtained using $\mathrm{CCl}_{4}$. No dopant is necessary with $\mathrm{CH}_{2} \mathrm{Cl}_{2}$, albeit the intensity slightly increases with tol-

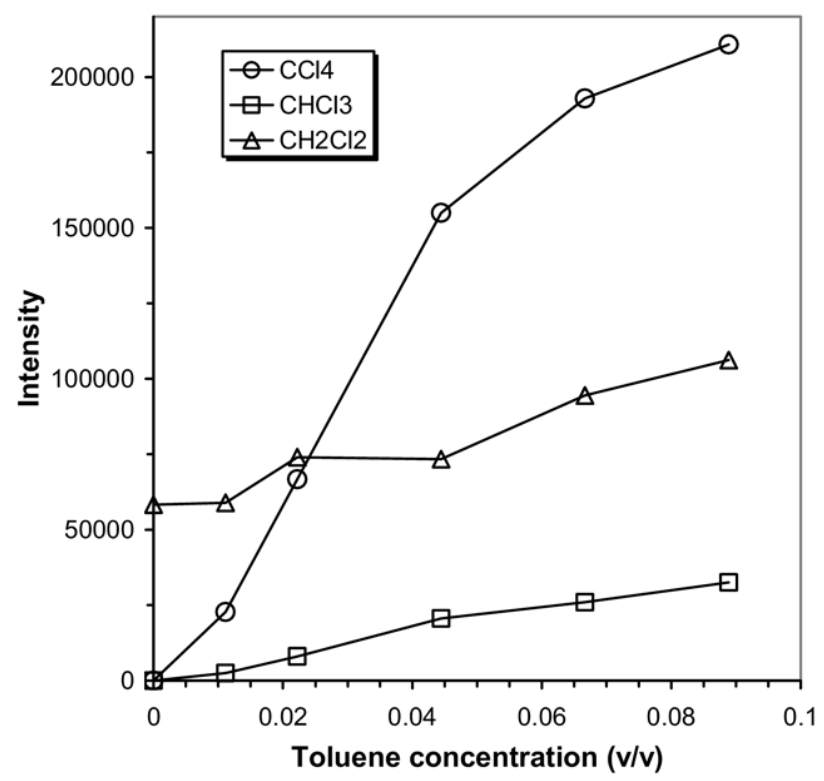

Figure 3. Dependence of the signal intensity recorded in solvents $\mathrm{CCl}_{4}, \mathrm{CHCl}_{3}$, and $\mathrm{CH}_{2} \mathrm{Cl}_{2}$ for monohydroxypolyisobutylene (PIB$\mathrm{OH})$ on the toluene concentration. The toluene concentrations represent the volume fractions of toluene with respect to the total (sample and carrier) feed. The concentration of PIB-OH in the sample feed was $0.5 \mathrm{mM}$. (Total flow rate: $225 \mu \mathrm{L} / \mathrm{min}$ ). 
uene concentration. These findings were also obtained for the other two PIB derivatives, i.e., for HO-PIB-OH and $=$-PIB- $=$. The observation that no toluene was required to obtain $\mathrm{APPI}(-)$-MS signal in $\mathrm{CH}_{2} \mathrm{Cl}_{2}$ can be explained in several ways: (1) $\mathrm{CH}_{2} \mathrm{Cl}_{2}$ contained an unidentified impurity that might act as dopant, (2) vacuum UV (VUV)-active species may be formed in situ upon the effect of APPI and in the possible presence of $\mathrm{O}_{2}$, or (3) $\mathrm{CH}_{2} \mathrm{Cl}_{2}$ itself is able to dissociate to produce $\mathrm{Cl}^{-}$ions in a subsequent reaction upon irradiation with VUV photons of $10.6 \mathrm{eV}$. If case (3) is true, the ionization potential (IP) of $\mathrm{CH}_{2} \mathrm{Cl}_{2}$ must be below $10.6 \mathrm{eV}$. However, the literature value for the IP of $\mathrm{CH}_{2} \mathrm{Cl}_{2}$ is $11.32 \mathrm{eV}$ [32]; therefore, the process described in case (3) seems unlikely.

It was observed that the hydroxyl-functionalized PIB derivatives, i.e., $\mathrm{HO}-\mathrm{PIB}-\mathrm{OH}$ and $\mathrm{PIB}-\mathrm{OH}$, produce fragment ions (to some extent) by eliminating an $\mathrm{H}_{2} \mathrm{O}$ molecule from the chain-end under APPI(-)-MS conditions. We postulate that such fragmention takes place during evaporation in the vaporizer, which is initiated by a thermal process. The extent of fragmentation (R) can be expressed as the fraction of the fragmented oligomers to the total ones using the corresponding signal intensities, and $\mathrm{R}$ can be given by eq 1 as (assuming equal ionization probabilities for all oligomers):

$$
\mathrm{R}=\sum S_{i,-\mathrm{H} 2 \mathrm{O}} /\left(\sum S_{i,-\mathrm{H} 2 \mathrm{O}}+\sum S_{i}\right),
$$

where $S_{i}$ and $S_{i,-\mathrm{H} 2 \mathrm{O}}$ stand for the signal intensity of $i$ th oligomers and that of its fragment ions formed by the loss of a water molecule, respectively.

The intensities are summed for all of the oligomers appearing in the APPI(-)-MS spectra. Figure 4 shows the dependences of $\mathrm{R}$ upon the toluene concentrations and the solvents.

As can be seen in Figure 4, toluene has no significant influence on the value of $R$ over the investigated concentration range. Nevertheless the solvent does have an effect. In $\mathrm{CCl}_{4}$ and $\mathrm{CHCl}_{3}$, fragmentation with $R=\sim 0.15$ and $\sim 0.18$, respectively, can be observed. However, the highest extent of fragmentation was found in $\mathrm{CH}_{2} \mathrm{Cl}_{2}(\mathrm{R}=\sim 0.4)$. The trend for the fragmentation, $\mathrm{CCl}_{4}<\mathrm{CHCl}_{3}<\mathrm{CH}_{2} \mathrm{Cl}_{2}$, is in line with the increasing volatility of these solvents.

\section{Mechanistic and Kinetic Considerations of Chlorinated Adduct Ion Formation in the Photoionization Region of APPI(-)-MS}

As discussed already, chloride ion attachment to the nonpolar PIB derivatives seems to be one of the most powerful ionization methods because each PIB monomer unit contains partially positively-charged $\mathrm{H}$ atoms to which a chloride ion can ligate. However, it was further established that both the end-groups and the solvent also affect the ionization efficiency to some extent. Therefore, it seems reasonable to assume that,

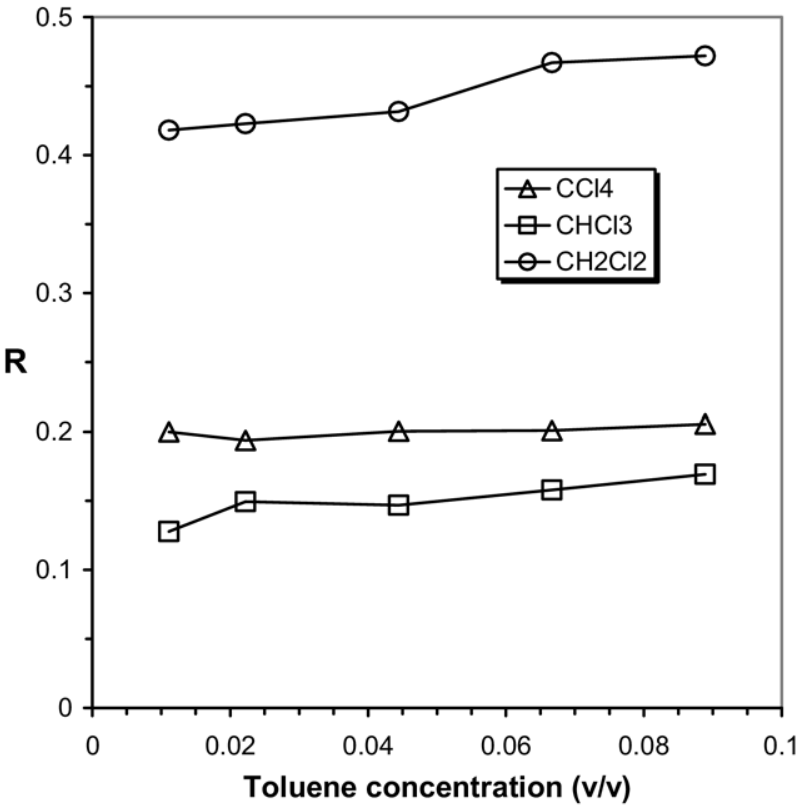

Figure 4. Variation of the extent of fragmentation $(R)$ for dihydroxypolyisobutylene (HO-PIB-OH) as a function of the toluene concentration recorded in solvents $\mathrm{CCl}_{4}, \mathrm{CHCl}_{3}$, and $\mathrm{CH}_{2} \mathrm{Cl}_{2}$. For the definition of $\mathrm{R}$, see eq 1 The concentration of HO-PIB-OH in the sample feed was $0.5 \mathrm{mM}$. The toluene concentrations represent the volume fractions of toluene with respect to the total (sample and carrier) feed. (Total flow rate: $225 \mu \mathrm{L} / \mathrm{min}$ ).

beyond thermodynamic considerations, the kinetics of some reactions occurring in the photoionization region (PI) of the APPI source (e.g., photoionization of the dopant and adduct ion formation) effectively alter the transfer of ions into the orifice of the MS instrument. Thus, charge recombination processes are all-important issues in determining signal intensity. A model describing the main features of the toluene-assisted ionization of PIBs in APPI(-)-MS is presented in Scheme 2.

According to Scheme 2, the photoionization of toluene takes place upon the irradiation of VUV photons, which generate radical toluene ions and electrons (R1). The thermal electron produced in process R1 may further react with the chlorinated solvents via dissociative electron capture to yield $\mathrm{Cl}^{-}$ions (R2), which can ligate to the polymer chains and give rise to the formation of adduct ions $[\mathrm{P}+\mathrm{Cl}]^{-}(\mathrm{R} 3)$. Processes similar to $\mathbf{R} \mathbf{1}$ and $\mathbf{R} \mathbf{2}$ have been suggested by Bruins and coworkers for the interpretation of some negative ion APPI-MS spectra [33]. In parallel with these events, however, charge recombination reactions of the toluene radical cations with the chloride ions $(\mathbf{R} 4)$ and the $[\mathrm{P}+\mathrm{Cl}]^{-}$ adduct ions (R5) may occur because the APPI-source is practically field-free.

In the following, we will describe the dependence of the signal intensity on the toluene (dopant) concentration. To achieve this goal, the photoionization region (PI) of the APPI source, i.e., the illuminated volume, will be treated as though it resembles a continuously stirred tank reactor (CSTR). In this consideration, the PI 
Photoionization

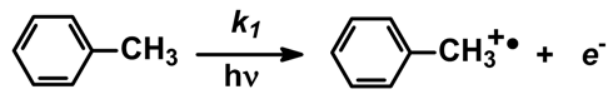

Dissociative elecron-capture

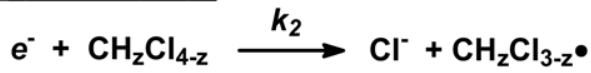

Adduct ion formation

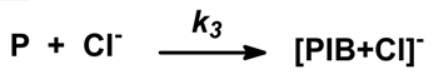

(R3)

Charge-recombination reactions

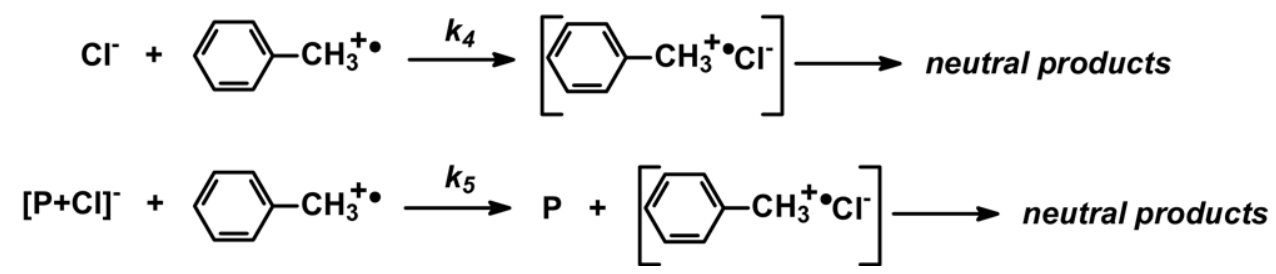

Scheme 2. Proposed mechanism for the formation of the adduct ion $[\mathrm{P}+\mathrm{Cl}]^{-}$in the presence of toluene and chlorinated solvents (where $\mathrm{P}$ stands for the polyisobutylene derivatives HO-PIB-OH, $=$ $-\mathrm{PIB}-=$ and PIB-OH and $z=0,1$, and 2).

region can be regarded as a "reactor" with connected vapor inlet and outlet flows. The volume of the PI region is $\sim 0.5 \mathrm{~cm}^{3}$ (data were obtained from the manufacturer). The vapor inlet flow rate $\left(k_{o}, \mathrm{~s}^{-1}\right)$ can be calculated from the total vapor volumetric flow rate $\left(v_{f l}\right.$, $\left.\mathrm{cm}^{3} \mathrm{~s}^{-1}\right)$ and the volume of the PI region $\left(V_{P I}, \mathrm{~cm}^{3}\right)$, as indicated in

$$
k_{o}=v_{f l} / V_{P I}
$$

Considering the total vapor volumetric flow rate, which is $\sim 50 \mathrm{~cm}^{3} / \mathrm{s}(\sim 3 \mathrm{~L} / \mathrm{min})$, and the volume of the PI region, a value of $\sim 100 \mathrm{~s}^{-1}$ can be calculated for $k_{\mathrm{o}}$.

As shown for APPI, the rate of photon absorption in the gas-phase $[34,35]$ by the dopant molecules $\left(I_{D}\right.$, photons/s) in a mixture composed of dopant and solvent molecules with number densities of $n_{D}$ and $n_{S}$ (particles $/ \mathrm{cm}^{3}$ ), respectively, can be given by

$$
I_{D}=I_{o} \frac{\sigma_{D} n_{D}}{\sigma_{D} n_{D}+\sigma_{S} n_{S}}\left\{1-\exp \left[-L\left(\sigma_{D} n_{D}+\sigma_{S} n_{S}\right)\right]\right\},
$$

where $I_{o}$ is the incident VUV-light intensity, $\sigma_{D}$ and $\sigma_{S}$ are the photon absorption cross-sections $\left(\mathrm{cm}^{2}\right)$ for the dopant and the solvent, respectively, and $L$ is the path length $(\mathrm{cm})$ across the photoionization region.

Applying eq 3 to our APPI-source and conditions in our particular case, we calculated $n_{D}$ and $n_{S}$ to be $4.7 \times$ $10^{15} \mathrm{~cm}^{-3}$ and $4.7 \times 10^{17} \mathrm{~cm}^{-3}$, respectively, when using $\mathrm{CCl}_{4}$ as a carrier liquid with a flow of $200 \mu \mathrm{L} / \mathrm{min}$, a sample liquid flow of $25 \mu \mathrm{L} / \mathrm{min}$ with a toluene concentration of $0.1 \mathrm{vol} / \mathrm{vol}$ and a total vapor volumetric flow of $3 \mathrm{~L} / \mathrm{min}$. Using the photoabsorption crosssections for toluene $[35,36]$ and $\mathrm{CCl}_{4}$ [37], which are 5.1 $\times 10^{-17} \mathrm{~cm}^{2}$ and $6.3 \times 10^{-17} \mathrm{~cm}^{2}$, respectively, and a path length of $0.5 \mathrm{~cm}$, one can calculate $L\left(\sigma_{D} n_{D}+\right.$ $\left.\sigma_{S} n_{S}\right)$ to be $\sim 15$ and observe that $\sigma_{D} n_{D} \ll \sigma_{S} n_{S}$; therefore, eq 3 reduces to eq 4 (the cross-sections for VUV photons $10 \mathrm{eV}$ and $10.6 \mathrm{eV}$ were intensity-weighted):

$$
I_{D}=a n_{D}
$$

where $\alpha=\frac{I_{O} \sigma_{D}}{\sigma_{S} n_{S}}$.

Equation 4 suggests that the rate of the photoabsorption by the dopant changes linearly with the dopant concentration. Within this estimation, $n_{S}$ is practically constant due to the small-volume variations of toluene in the feed (at most $10 \%$ at a constant total flow rate of 225 $\mu \mathrm{L} / \mathrm{min})$. Using the value of $I_{o}$, which is $10^{15}$ photons $/ \mathrm{s}$ in our case, the value of $\alpha$ in eq 4 can be calculated as $\sim 2$ $\times 10^{-3} \mathrm{~cm}^{3} \mathrm{~s}^{-1}$ (value for $I_{o}$ was obtained from the manufacturer). The rate of dopant ion generation $\left(R_{D}\right.$, ions/s) [35] is given by

$$
R_{D}=I_{D} \phi=\alpha n_{D} \phi,
$$

where $\phi$ stands for the total quantum ionization yield.

The value of $\phi$ is basically determined by several events that occur in the photoionization region; most of those include direct and autoionization reactions of the dopant, as well as collisional quenching of the photoexcited dopant molecules by the solvent and background gas molecules. Considering the complexity of these reactions, it would be very difficult to predict the 
value of $\phi$. Therefore, we assume $\phi$ to be $\sim 1$ for the sake of simplicity, i.e., a very efficient direct photoionization of toluene takes place. On the other hand, the rate of dopant ion generation $\left(R_{D}\right)$ is equal to the rate of chloride ion production $\left(R_{C l}\right)$ within a "reactor" (i.e., PI region) of volume $V_{P I}$ assuming that the electrons formed in process R1 (see Scheme 2) are captured rapidly by the solvent molecules followed by ejection of chloride ions (R2), and the rate of ion generation (ions $\mathrm{cm}^{-3} \mathrm{~s}^{-1}$ ) can be given by eq 6 using eqs 4 and 5 :

$$
R_{D}=R_{C l}=k_{l} n_{D},
$$

where $k_{1}=\alpha / V_{P I}$.

According to eq 6, a value of $\sim 4 \times 10^{-3} \mathrm{~s}^{-1}$ was calculated for $k_{1}$. For the reactions occurring in the PI region of the APPI-source presented in Scheme 2, the following set of differential equations can be written:

$$
\begin{aligned}
& d n_{D} / d t=k_{\mathrm{o}}\left(n_{D, \mathrm{o}}-n_{D}\right)=k_{1} n_{D} \\
& \mathrm{~d} n_{+} / \mathrm{d} t=k_{l} n_{D}-k_{4} n_{+} n_{C l}-k_{s} n+n_{P C l}-k_{o} n_{+} \\
& \mathrm{d} n_{C l} / \mathrm{d} t=k_{l} n_{D}-k_{3} n_{p} n_{C l}-k_{4} n_{+} n_{C l}-k_{\mathrm{o}} n_{C l} \\
& \mathrm{~d} n_{P C l} / \mathrm{d} t=k_{3} n_{P} n_{C l}-k_{S} n_{+} n_{P C l}-k_{o} n_{P C l} \\
& \mathrm{~d} n_{p} / \mathrm{d} t=k_{\mathrm{o}}\left(n_{P .0}-n_{P}\right)-k_{3} n_{P} n_{C l}+k_{5} n_{+} n_{P C l}
\end{aligned}
$$

where $k_{1}, k_{3}, k_{4}$, and $k_{5}$ are the rate constants of the corresponding reactions shown in Scheme 2 and $k_{\mathrm{o}}$ is the inlet vapor flow rate (for $k_{\mathrm{o}}$ and $k_{1}$ see the above discussions). The values $n_{D}, n_{+}, n_{C l}, n_{P C l}$ and $n_{P}$ are the number densities of dopant, photoionized dopant ion, chloride ion, adduct of PIB with chloride ion ([P + $\mathrm{Cl}]^{-}$), and PIB in the PI "reactor", respectively, and $n_{D, o}$ and $n_{P, o}$ are the number densities of the dopant (toluene) and PIB in the vapor feed (inlet).

Escape of the reactants and products from the "reactor" by diffusion processes, i.e., diffusion losses, are not considered here, albeit these may operate to some extent because the PI "reactor" has no wall. As pointed out by one of our reviewers, another issue that is not taken into account in the model is the in-source fragmentation of chloride adducts. However, our instrument has a double-stage ion funnel that induces less fragmentation compared to the traditional nozzle/ skimmer configuration. In all experiments, the insource energy was set to " 0 ". To check the stability of the chloride adducts, the in-source energies were varied from 0 to $12 \mathrm{eV}$. No considerable decrease in signal intensities was observed, indicating that these adducts are stable enough to be transported towards the $\mathrm{Q}$ region of the instrument without significant decomposition.

Considering the solution concentration and liquid inlet flow rate of PIB $(\sim 0.5 \mathrm{mM}, 25 \mu \mathrm{L} / \mathrm{min})$ and the total volumetric flow rate $(\sim 3 \mathrm{~L} / \mathrm{min})$, the value of $n_{P, o}$ in the vapor inlet was calculated to be $\sim 2.5 \times 10^{12} \mathrm{~cm}^{-3}$. In the PI "reactor", a steady-state is established, enabling differential eqs 7-11 to reduce to algebraic equations. However, we chose to solve differential eqs 7-11 numerically because calculations of time-dependent variations of number densities will be required later. (An approach to solve the steady-state eqs 7-11 analytically and handle the time-dependent variations of number densities after the PI region is outlined in the Appendix.) Because the APPI source is practically fieldfree, no separation of the opposite charges that are generated during irradiation takes place. After the ions have left the PI regions, i.e., during their transfer to the orifice of the MS instrument, charge-recombination reactions become more important, which results in a decrease in the analyte concentration. The time $(\tau)$ required for the ions to arrive at the orifice where they will be abruptly separated due to the presence of an electric field depends on the distance between the PI "reactor" and the orifice and the linear velocity of the vapor flow (total volumetric flow). For our case, $\tau$ was estimated to be $\sim 10 \mathrm{~ms}$. [The linear velocity of the vapor flow was estimated to be $\sim 170$ $\mathrm{cm} / \mathrm{s}$ based on the total volumetric flow $\sim 3 \mathrm{~L} / \mathrm{min}$, the diameter of the vapor conduit $(6.1 \mathrm{~mm})$ and the distance between the PI and the orifice $(1.6 \mathrm{~cm})]$.

To simulate the dependence of the signal intensities on the toluene concentrations, eqs 7-11 were solved numerically and calculated for the time period required for the system to reach the steady-state (typically 80 $\mathrm{ms}$ ). The values of $k_{o}$ and $k_{1}$ were then set to zero (this simulates the case when the reactant and product ions have left the PI "reactor") and calculated further for an additional time period of $10 \mathrm{~ms}$.

In addition, a linear relationship between the signal intensity $(S)$ of the $[\mathrm{P}+\mathrm{Cl}]^{-}$adduct ions and $n_{P C l}$, was assumed, i.e.,

$$
S=C n_{P C l}
$$

where $C$ is a constant.

The number densities of $n_{P C l}$ obtained after a time period of $10 \mathrm{~ms}$ were converted to intensities using eq 12 , and then the intensity values were plotted as a function of the toluene concentration. The number densities of the toluene molecules were simply calculated by considering the sample flow rate $(25 \mu \mathrm{L} / \mathrm{min})$, the actual toluene-content of the sample flow, as well as the total volumetric flow $(3 \mathrm{~L} / \mathrm{min})$.

Figure 5 shows the experimental and calculated plots for the variations of signal intensities on the toluene concentrations for $=-\mathrm{PIB}-=$ in $\mathrm{CCl}_{4}$. The rate constants used to calculate the plot presented in Figure 5 are summarized in Table 1.

As evident in Figure 5, there is an acceptable agreement between the experimental and calculated values. The calculated intensity curve was obtained by manually varying the values of rate constants $k_{3}, k_{4}$, and $k_{5}$ to match the experimental data. 


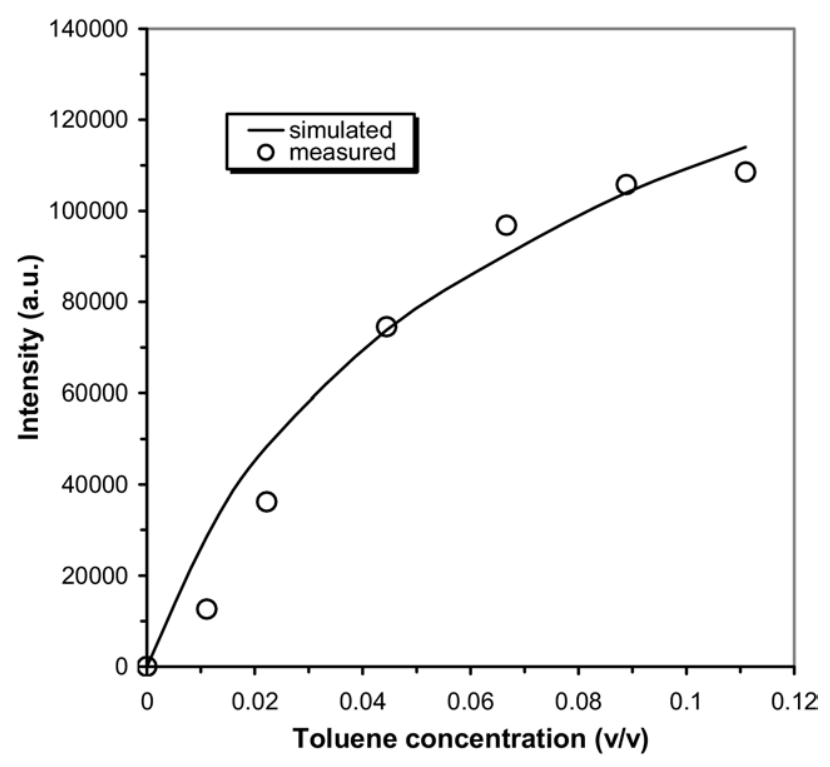

Figure 5. Measured and calculated dependence of APPI(-)-MS intensity on the liquid toluene concentration for diolefinpolyisobutylene ( $=$-PIB- $=)$ in $\mathrm{CCl}_{4}$. The toluene concentrations represent the volume fractions of toluene with respect to the total (sample and carrier) feed. The concentration of $=-$ PIB- $=$ in the sample feed was $0.5 \mathrm{mM}$. (Total liquid flow rate: $225 \mu \mathrm{L} / \mathrm{min}$.) $\left(C=3 \times 10^{-7}\right.$.)

As was mentioned above, the number density of the $[\mathrm{P}+\mathrm{Cl}]^{-}$ions in the vapor flow decreases in time after the ions have left the PI region. For example, the number density of $[\mathrm{P}+\mathrm{Cl}]^{-}$in the vapor at the steady-state was calculated to be $3.6 \times 10^{11} \mathrm{~cm}^{-3}$ at a toluene concentration of $0.067 \mathrm{vol} / \mathrm{vol}$ and a total liquid flow of $225 \mu \mathrm{L} / \mathrm{min}$. This value decreases to $3 \times 10^{11}$ $\mathrm{cm}^{-3}$ after $10 \mathrm{~ms}$ of reaction time. Furthermore, we found that the final number density of $[\mathrm{P}+\mathrm{Cl}]$ - is very sensitive to rate constants $k_{4}$ and $k_{5}$, i.e., to the rate constants of the charge-recombination reactions, and less sensitive to the value of $k_{1}$. Considering eqs 4 and 5, values of $\sim 1 \times 10^{-3}, \sim 5 \times 10^{-3}$, and $\sim 4 \times 10^{-3} \mathrm{~s}^{-1}$ can be calculated for $k_{1}$ in $\mathrm{CH}_{2} \mathrm{Cl}_{2}, \mathrm{CHCl}_{3}$, and $\mathrm{CCl}_{4}$, respectively. The photoabsorption cross-sections for $\mathrm{CH}_{2} \mathrm{Cl}_{2}$ $\left(1.3 \times 10^{-16} \mathrm{~cm}^{-2}\right)$ and $\mathrm{CHCl}_{3}\left(4.2 \times 10^{-17} \mathrm{~cm}^{-2}\right)$ were taken from references [24, 32]. Based on the model calculations, it can be expected that the resulting APPI(-)-MS signal intensities increase in the order of $\mathrm{CH}_{2} \mathrm{Cl}_{2}<\mathrm{CCl}_{4}<\mathrm{CHCl}_{3}$. However, this trend is not strictly in line with that seen in Figure 2. The reason for this may be as follows: (1) The quantum yield $(\phi)$ in eq 5 is lower than 1 (this is a reasonable assumption) and may vary significantly with the solvents applied, overcompensating the predicted trend; (2) the efficiency of the electron capture in process $\mathbf{R} \mathbf{2}$ presented in Scheme 2 is highly solvent-dependent, which is not considered in this simplified model. Although the model proposed in this paper contains relatively large uncertainties associated with the values of some rate constants, the agreement between the theoretical and experimental data is acceptable.
In addition, the model proposed here may be generally capable of describing the APPI ionizations of other polymers as well.

\section{Conclusions}

Three different polyisobutylene derivatives were investigated in both the positive and negative ion modes under APPI conditions. In the positive ion mode, each of the three PIBs form [PIB $+\mathrm{H}]^{+}$adduct ions; however, extensive fragmentation of these ions was observed. In the negative ion mode of APPI using chlorinated solvents and toluene as a dopant, the formation of adducts of PIBs with chloride ions was recognized with minimal or no fragmentation, allowing for the exact determination of the end-groups and repeat units. The influences of the end-groups, the solvent, and the dopant (toluene) concentration on the resulting APPI(-)-MS signal intensities were also observed and discussed. Moreover, the effect of the end-groups proved to be less significant than in MALDI or ESI. It was assumed that the chloride ion attached itself to the positively charged $\mathrm{H}$ atoms of the PIB methyl groups. Therefore, it can be expected that polyisobutylenes with other end-groups, e.g., those of saturated bonds, can also be analyzed by APPI(-)-MS. The other advantage of this technique is that nonpolar solvents and solvent mixtures in which PIBs and other polymers of similar polarity can be dissolved are compatible with APPI. Based on the experimental results, models involving (1) photoionization of toluene, (2) formation of chloride ions from chlorinated solvents by dissociative electron capture, (3) formation of chlorinated adduct ions and charge recombination reactions between the toluene radical cation, (4) chloride ion, and (5) chlorinated adduct ions were proposed. To describe the signal intensity variations against the toluene concentrations, the above model was applied, and the photoionization region of the APPI-source was treated as a continuously stirred tank reactor. The rate constant of process (i) was calculated using the extended Lambert-Beer equation. The other rate constants involved in the model were estimated by manual fitting the calculated values to the experimental data. Despite the fact that the model proposed may involve relatively large uncertainties in the values of the estimated rate constants, the agreement between the theory and the experiments is quite good.

Table 1. Rate constants used to calculate the signal intensity versus toluene concentration plot presented in Figure 5

\begin{tabular}{ll}
\hline Rate constant $^{\mathrm{a}}$ & \multicolumn{1}{c}{ Value } \\
\hline \hline$k_{0}$ & $100 \mathrm{~s}^{-1}$ \\
$k_{1}$ & $4 \times 10^{-3} \mathrm{~s}^{-1}$ \\
$k_{3}$ & $10^{-8} \mathrm{~cm}^{-3} \mathrm{~s}^{-1}$ \\
$k_{4}$ & $10^{-7} \mathrm{~cm}^{-3} \mathrm{~s}^{-1}$ \\
$k_{5}$ & $5 \times 10^{-11} \mathrm{~cm}^{-3} \mathrm{~s}^{-1}$ \\
\hline
\end{tabular}

a The rate constants correspond to those presented in Scheme 2. 
The proposed model can be generally applied to describe APPI ionizations of other polymers.

\section{Acknowledgments}

The authors acknowledge financial support for this work by grants K-62,213 and MU-00,204/2001 given by OTKA (National Scientific Research Fund, Hungary) and grants RET-006/2004 and GVOP-3.2.1.-2004-04-0152/3.0.

\section{Appendix}

It follows from eq 7 that at steady-state conditions, i.e., when $\mathrm{d} n_{D} / \mathrm{d} t=0$, the steady-state concentration of the toluene dopant $\left(n_{D, s s}\right)$ is

$$
n_{D, S S}=\frac{k_{o}}{k_{o}+k_{1}} n_{D, o}
$$

From eqs 8, 9, and 11, eq 14 can be derived, i.e.,

$$
n_{P, 0}=n_{P, s s}+n_{+, s s}-n_{C l, s s}
$$

When the rates of chloride ion-producing and consuming reactions are balanced and the pseudo rate constants of the latter are much higher than those of the chloride ion-producing reactions, it is expected that the steady-state concentration of $\mathrm{Cl}^{-}$ions $\left(n_{C l, s s}\right)$ is much lower than that of $n_{P C l, s s}$ and that $n_{+, s s,}$ and $n_{P C l, s s} \approx$ $n_{+, s s}$. Taking into account that $n_{P C l, s s} \approx n_{+, s s}$ and $n_{P C l, s s}$ $\gg n_{C l, s s}$ eq 14 reduces to:

$$
n_{P, s s} \approx n_{P, o}-n_{P C l, s s}
$$

Substituting eq 15 into eq 11, the steady-state number density of chloride ions $\left(n_{C l, s s}\right)$ can be given by

$$
n_{C l, s s} \approx \frac{k_{5} n_{P C I, s s}^{2}+k_{o} n_{P C l, s s}}{k_{3}\left(n_{P, o}-n_{P C l, s s}\right)}
$$

Further substitution of eq 16 into eq 8 yields a cubic equation for $n_{P C l, s s}$ (eq 17):

$$
\begin{aligned}
& k_{5}\left(k_{3}-k_{4}\right) n_{P C l, s s}^{3}+\left(k_{o} k_{3}-k_{o} k_{4}-k_{3} k_{5} n_{P, o}\right) n_{P C l, s s}^{2} \\
& -\left(\frac{k_{o} k_{1} k_{3}}{k_{o}+k_{1}} n_{D, o}+k_{o} k_{3} n_{P, o}\right) n_{P C l, s s}+\frac{k_{o} k_{1} k_{3} n_{D, o} n_{P, o}}{k_{o}+k_{1}}=0
\end{aligned}
$$

Substitution of the corresponding rate constants and the values of $n_{P, o}$ and $n_{D, o}$ into eq 12 and solving eq 12 using, e.g., a Cardano-formula, the value of $n_{P C l, s s}$ can be determined.

The dominant process between the PI region and the orifice of the MS instrument is the recombination of the toluene radical cations with the $\left[\mathrm{P}+\mathrm{Cl}^{-}\right.$adduct. The rate of this recombination reaction can be given by

$$
\mathrm{d} n_{P C l} / \mathrm{d} t=-k_{5} n_{P C l}^{2}
$$

Integration of eq 18 from $t=0$ to $\tau$ and from the initial number density of $[\mathrm{P}+\mathrm{Cl}]^{-}$, i.e., $n_{P C l, s s}$ to $n_{P C l}$, yields eq 19 , by which the final number density of $[\mathrm{P}+\mathrm{Cl}]^{-}$ entering the mass spectrometer after transfer time $\tau$ can be approximated.

$$
n_{P C l} \approx \frac{n_{P C l, s s}}{1+k_{5} n_{P C l, s s} \tau}
$$

\section{References}

1. Karas, M.; Hillenkamp, F. Laser Desorption Ionization of Proteins with Molecular Masses Exceeding 10,000 Daltons. Anal. Chem. 1988, 60, 2299-2301.

2. Tanaka, K.; Waki, H.; Ido, Y.; Akita, S.; Yoshida, T. Protein and Polymer Analyses up to $m / z 100,000$ by Laser Ionization Time-of-Flight Mass Spectrometry. Rapid Commun. Mass Spectrom 1988, 2, 151-153.

3. Wong, S. F.; Meng, C. K.; Fenn, J. B. Multiple Charging in Electrospray Ionization of Poly(Ethylene Glycols). J. Phys. Chem. 1988, 92, 546-550.

4. Varray, S.; Aubagnac, J. L.; Lamaty, F.; Lazaro, R.; Martinez, J.; Enjalbal, C. Poly(Ethylene Glycol) in Electrospray Ionization (ESI) Mass Spectrometry. Analusis 2000, 28, 263-268.

5. Bogan, M. J.; Agnes, G. R. Poly(Ethylene Glycol) Doubly and Singly Cationized by Different Alkali Metal Ions: Relative Cation Affinities and Cation-Dependent Resolution in a Quadrupole Ion Trap Mass Spectrometer. J. Am. Soc. Mass Spectrom. 2002, 13, 177-186.

6. Okuno, S.; Ohmoto, M.; Arakawa, R. Analysis of Polypropyleneglycols Using Electrospray Ionization Mass Spectrometry. Effects of Cationizing Agents on the Mass Spectra. Eur. J. Mass Spectrom. 2003, 9, 97-103.

7. Kéki, S.; Nagy, L.; Deák, G.; Zsuga, M. Multiple Charging of Poly(Propylene Glycol) by Binary Mixtures of Cations in Electrospray. J. Am. Soc. Mass Spectrom. 2005, 16, 152-157.

8. Kéki, S.; Szilágyi, L. S.; Deák, G.; Zsuga, M. Effects of Different Alkali Metal Ions on the Cationization of Poly(Ethylene Glycol)s in MatrixAssisted Laser Desorption/Ionization Mass Spectrometry: A New Selectivity Parameter. J. Mass Spectrom. 2002, 37, 1074-1080.

9. Rashidzadeh, H.; Wang, Y.; Guo, B. C. Matrix Effects on Selectivities of Poly(Ethylene Glycol)s for Alkali Metal Ion Complexation in MatrixAssisted Laser Desorption/Ionization. Rapid Commun. Mass Spectrom. 2000, 14, 439-443.

10. Wang, Y.; Rashidzadeh, H.; Gou, B. C. Structural Effects on Polyether Cationization by Alkali Metal Ions in Matrix-Assisted Laser Desorption/Ionization. J. Am. Soc. Mass Spectrom. 2000, 11, 639-643.

11. Macha, S. F.; Limbach, P. A.; Savickas, P. J. Application of Nonpolar Matrices for the Analysis of Low Molecular Weight Nonpolar Synthetic Polymers by Matrix-Assisted Laser Desorption/Ionization Time-ofFlight Mass Spectrometry. J. Am. Soc. Mass Spectrom. 2000, 11, 731-737.

12. Kéki, S.; Deák, G.; Zsuga, M. Copper(I) Chloride: A Simple Salt for Enhancement of Polystyrene Cationization in Matrix-Assisted Laser Desorption/Ionization Mass Spectrometry. Rapid Commun. Mass Spectrom. 2001, 15, 675-678.

13. Deery, M. J.; Jennings, K. R.; Jasieczek, C. B.; Haddleton, D. M.; Jackson, A. T.; Yates, H. T.; Scrivens, J. H. A. Study of Cation Attachment to Polystyrene by Means of Matrix-Assisted Laser Desorption/Ionization and Electrospray Ionization-Mass Spectrometry. Rapid Commun. Mass Spectrom. 1997, 11, 57-62.

14. Jackson, A. T.; Yates, H. T.; MacDonald, W. A.; Scrivens, J. H.; Critchley, G.; Brown, J.; Deery, M. J.; Jennings, K. R.; Brookes, C. Time-Lag Focusing and Cation Attachment in the Analysis of Synthetic Polymers by Matrix-Assisted Laser Desorption Ionization Time-of-Flight Mass Spectrometry. J. Am. Soc. Mass Spectrom. 1997, 8, 132-139.

15. Kéki, S.; Deák, G.; Mayer-Posner, F. J.; Zsuga, M. MALDI-TOF MS Characterization of Dihydroxy Telechelic Polyisobutylene. Macromol. Rapid Commun. 2000, 21,770-774.

16. Kéki, S.; Nagy, M.; Deák, G.; Lévai, A.; Zsuga, M. Dimethyldioxirane as a New and Effective Oxidation Agent for the Epoxidation of $\alpha, \theta$ Di(Isobutenyl)Polyisobutylene: A Convenient Synthesis of $\alpha, \theta-\mathrm{Di}(2-$ Methyl-3-Hydroxypropyl)Polyisobutylene. J. Polym. Sci. Part A Polym. Chem. 2002, 40, 3974-3986.

17. Kéki, S.; Nagy, M.; Deák, G.; Zsuga, M.; Herczegh, P. Matrix-Assisted Laser Desorption/Ionization Mass Spectrometric Study of Bis(Imidazole-1-Carboxylate) End-functionalized Polymers. J. Am. Soc. Mass Spectrom. 2003, 14, 117-123.

18. Nagy, M.; Kéki, S.; Orosz, L.; Deák, G.; Herczegh, P.; Lévai, A.; Zsuga, M. Novel and Simple Synthesis of Carboxyl-Terminated Polyisobutylenes. Macromolecules 2005, 38, 4043-4046.

19. Ji, H. N.; Sato, N.; Nakamura, Y.; Wan, Y. N.; Howell, A.; Thomas, Q. A.; Storey, R. F.; Nonidez, W. K.; Mays, J. W. Characterization of Polyisobutylene by Matrix-Assisted Laser Desorption Ionization Time-of-Flight Mass Spectrometry. Macromolecules 2002, 35, 1196-1199. 
20. Harrison, J. J.; Mijares, C. M.; Cheng, M. T.; Hudson, J. Negative Ion Electrospray Ionization Mass Spectrum of Polyisobutenylsuccinic Anhydride: Implications for Isobutylene Polymerization Mechanism. Macromolecules 2002, 35, 2494-2500.

21. Syage, J. A.; Evans, M. D.; Hanold, K. A. Photoionization Mass Spectrometry. Am. Lab. 2000, 32, 24-29.

22. Robb, D.; Covey, T.; Bruins, A. Atmospheric Pressure Photoionization: An Ionization Method for Liquid Chromatography-Mass Spectrometry. Anal. Chem. 2000, 72, 3653-3659

23. Kauppila, T. J.; Kuuranne, T.; Meurer, E. C.; Eberlin, M. N.; Kotiaho, T.; Kostiainen, R. Atmospheric Pressure Photoionization Mass Spectrometry. Ionization Mechanism and the Effect of Solvent on the Ionization of Naphthalenes. Anal. Chem. 2002, 74, 5470-5479.

24. Short, L. C.; Cai, S.-S.; Syage, J. A. APPI-MS: Effects of Mobile Phases and VUV Lamps on the Detection of PAH Compounds. J. Am. Soc. Mass Spectrom. 2007, 18, 589-599.

25. Moriwaki, H.; Ishitake, M.; Yoshikawa, S.; Miyakoda, H.; Alary, J. F. Determination of Polycyclic Aromatic Hydrocarbons in Sediment by Liquid Chromatography-Atmospheric Pressure Photoionization-Mass Spectrometry. Anal. Sci. 2004, 20, 375-377.

26. Cai, S. S.; Syage, J. A. Comparison of Atmospheric Pressure Photoionization, Atmospheric Pressure Chemical Ionization, and Electrospray Ionization Mass Spectrometry for Analysis of Lipids. Anal. Chem. 2006, 78, 1191-1199

27. Cai, S. S.; Syage, J. A. Atmospheric Pressure Photoionization Mass Spectrometry for Analysis of Fatty Acid and Acylglycerol Lipids. J. Chromatoor. A 2006, 1110, 15-26.

28. Delobel, A.; Roy, S.; Touboul, D.; Gaudin, K.; Germain, D. P.; Baillet, A.; Brion, F.; Prognon, P.; Chaminade, P.; Laprevote, O. Atmospheric Pressure Photoionization Coupled to Porous Graphitic Carbon Liquid Chromatography for the Analysis of Globotriaosylceramides. Application to Fabry Disease. J. Mass Spectrom. 2006, 41, 50-58.
29. Greig, M. J.; Bolanos, B.; Quenzer, T.; Bylund, J. M. R. Cyclotron Resonance Mass Spectrometry Using Atmospheric Pressure Photoionization for High-Resolution Analyses of Corticosteroids. Rapid Commun. Mass Spectrom 2003, 17(24), 2763-2768.

30. Kauppila, T. J.; Nikkola, T.; Ketola, R. A.; Kostiainen, R. Atmospheric Pressure Photoionization-Mass Spectrometry and Atmospheric Pressure Chemical Ionization-Mass Spectrometry of Neurotransmitters. J. Mass Spectrom. 2006, 41, 781-789.

31. Trosken, E. R.; Straube, E.; Lutz, W. K.; Volkel, W.; Patten, C. Quantitation of Lanosterol and its Major Metabolite FF-MAS in an Inhibition Assay of CYP51 by Azoles with Atmospheric Pressure Photoionization Based LC-MS/MS. J. Am. Soc. Mass Spectrom. 2004, 15, 1216-1221.

32. Russel, B. R.; Edwards, L. O.; Raymonda, J. W. Vacuum Ultraviolet Absorption Spectra of the Chloromethanes. J. Chem. Phys. 1973, 59, 6577-6586.

33. Kauppila, T. J.; Kotiaho, T.; Kostiainen, R.; Bruins, A. P. Negative Ion-Atmospheric Pressure Photoionization Mass Spectrometry. I. Am. Soc. Mass Spectrom. 2004, 15, 203-211.

34. Robb, D. B.; Blades, M. W. Effects of Solvent Flow, Dopant Flow, and Lamp Current on Dopant-Assisted Atmospheric Pressure Photoionization (DA-APPI) for LC-MS. Ionization via Proton Transfer Damon B. J. Am. Soc. Mass Spectrom. 2005, 16, 1275-1290.

35. Robb, D. B.; Blades, M. W. Factors Affecting Primary Ionization in Dopant-Assisted Atmospheric Pressure Photoionization (DA-APPI) for LC/MS. J. Am. Soc. Mass Spectrom. 2006, 17, 130-138.

36. Shaw, D. A.; Holland, D. M. P.; MacDonald, M. A.; Hayes, M. A.; Shpinkova, L. G.; Rennie, E. E.; Johnson, C. A. F.; Parker, J. E.; von Niessen, W. An Experimental and Theoretical Study of the Spectroscopic and Thermodynamic Properties of Toluene. Chem. Phys. 1998, 230, 97-116

37. Ho, G. H. Absolute Photoabsorption Cross Section of $\mathrm{CCl}_{4}$ in the Energy Range 6 to $250 \mathrm{eV}$. Chem. Phys. 1998, 226, 101-111. 